\title{
Emodin induces apoptosis in human hepatocellular carcinoma HepaRG cells via the mitochondrial caspase-dependent pathway
}

\author{
XIAOXV DONG ${ }^{1 *}$, BORAN NI ${ }^{2 *}$, JING FU $^{3}$, XINGBIN YIN ${ }^{1}$, \\ LONGTAI YOU $^{1}$, XIN LENG $^{1}$, XIAO LIANG ${ }^{4}$ and JIAN NI ${ }^{1}$ \\ ${ }^{1}$ School of Chinese Materia Medica and ${ }^{2}$ School of Basic Medical Science, Beijing University of Chinese Medicine, \\ Beijing 100102; ${ }^{3}$ Beijing Institute of Traditional Chinese Medicine, Beijing Hospital of Traditional Chinese Medicine, \\ Capital Medical University, Beijing 100010; ${ }^{4}$ Shanghai Binuo Medical Instrument Co., Ltd., Shanghai 200000, P.R. China
}

Received September 26, 2017; Accepted February 12, 2018

DOI: $10.3892 /$ or.2018.6620

\begin{abstract}
Emodin-induced hepatotoxicity in vivo and in vitro has been gaining increasing attention. However, the exact molecular pathways underlying these effects remain poorly clarified. The aim of the present study was to evaluate the cytotoxic effect of emodin on HepaRG cells and to define the underlying mechanism. The results demonstrated that emodin evidently inhibited HepaRG cell growth in a dose- and time-dependent manner by blocking cell cycle progression in the $\mathrm{S}$ and $\mathrm{G} 2 / \mathrm{M}$ phase and by inducing apoptosis. Emodin treatment also resulted in generation of reactive oxygen species (ROS), which abrogated mitochondrial membrane potential (MMP). The above effects were all suppressed by antioxidants, such as $N$-acetylcysteine (NAC). Further studies by western blot analysis howed that emodin upregulated p53, p21, Bax, cyclin E, cleaved caspase-3, 8 and 9, and cleaved poly(ADP-ribose)polymerase (PARP). However, the protein expression of Bcl-2, cyclin A and CDK2 was downregulated. Taken together, our results suggest that emodin induces apoptosis via the mitochondrial apoptosis pathway through cell cycle arrest and ROS generation in HepaRG cells.
\end{abstract}

\section{Introduction}

Apoptosis is a highly regulated and genetically programmed cell death process. It is driven through the death receptor-mediated extrinsic pathway and mitochondrial-mediated intrinsic pathway (1-3), which plays a pivotal role in the programmed

Correspondence to: Professor Jian Ni, School of Chinese Materia Medica, Beijing University of Chinese Medicine, Beijing 100102, P.R. China

E-mail: njtcm@263.net

*Contributed equally

Key words: emodin, hepatotoxicity, reactive oxygen species, apoptosis, HepaRG cells cell death of mammalian cells (4). Reactive oxygen species (ROS) plays an important role in apoptosis by regulating the intrinsic mitochondrial apoptosis pathway (5). An increase in ROS production regulates Bcl-2 family members, such as Bax and $\mathrm{Bcl}-2$. Changes in the $\mathrm{Bax} / \mathrm{Bcl}-2$ ratio result in the release cytochrome $c$, which then activates caspase-3 and cleaves PARP, leading to cell death through the mitochondrial death pathway (6-8).

Emodin (1,3,8-trihydroxy-6-methylanthraquinone) (Fig. 1) is a naturally occurring anthraquinone derivative, which is found in a variety of tradition Chinese herbs including Rheum palmatum (9), Polygonum cuspidatum (10), Polygonum multiflorum (11) and Cassia occidentalis (12). Modern pharmacological studies have revealed that emodin possesses anti-proliferative effects on various cancer cells, such as pancreatic cancer (13), breast cancer (14), hepatocellular carcinoma (15), lung carcinoma (16), gastric carcinoma (17) and prostate cancer (18). Furthermore, this drug has also been reported to exhibit antiviral (19), antibacterial (20), anti-allergic (21), anti-osteoporotic (22), anti-diabetic (23), immunosuppressive (24) and neuroprotective (25) activities. Nevertheless, an increasing number of recently published studies have reported the deleterious effects of emodin in in vivo and in vitro investigations $(26,27)$. Panigrahi et al reported that emodin isolated from the methanol extracts of Cassia occidentalis might be one of its main hepatotoxic ingredients (28). Furthermore, an in vivo study demonstrated that emodin may be one of the primary chemical components in Rheum palmatum L. that causes hepatic and renal toxicity (29).

HepaRG cells, which are derived from a human hepatocellular carcinoma, express various CYPs and possess both the metabolic characteristics of primary human hepatocytes and the growth capacity of hepatic cell lines. It is useful for evaluating drug-induced hepatotoxicity and can be considered an ideal in vitro model for cytotoxicity investigation $(30,31)$. In the present study, we investigated the cytotoxicity of emodin in HepaRG cells and the underlying molecular mechanisms. Our data demonstrated that emodin induces apoptotic cell death in HepaRG cells through ROS production and activation of the intrinsic apoptosis pathway. 


\section{Materials and methods}

Materials and antibodies. Emodin (batch no. 4887, purity $>98.0 \%$ ) was obtained from Shanghai Standard Biotech Co., Ltd. (Shanghai, China). Emodin was dissolved in DMSO to a stock concentration of $40 \mathrm{mM}$ and stored at $4^{\circ} \mathrm{C}$. MTT was purchased from Bejing Biodee Biotechnology Co., Ltd. (Beijing, China). LDH assay kit, DAPI assay kit, NAC, Annexin V-FITC apoptosis assay kit, ROS assay kit, MMP assay kit, cell cycle assay kit were purchased from Beyotime (Nanjing, China). Antibodies for Bax (1:1,000; rabbit polyclonal; cat. no. 5023T), Bcl-2 (1:1,000; mouse polyclonal; cat. no. 15071), p53 (1:1,000; mouse polyclonal; cat. no. $2524 \mathrm{~T})$, p21 (1:1,000; rabbit polyclonal; cat. no. 2947T), cyclin A $(1: 1,000$; mouse polyclonal; cat. no. $4656 \mathrm{~T})$, cyclin $\mathrm{E}$ (1:1,000; mouse polyclonal; cat. no. 4129P), CDK2 (1:1,000; rabbit polyclonal; cat. no. 2546T), cleaved caspase-3 (1:1,000; rabbit polyclonal; cat. no. 9661T), cleaved caspase-9 (1:1,000; rabbit polyclonal; cat. no. 9509T), cytochrome $c(1: 1,000$; rabbit polyclonal; cat. no. 4280T) and PARP (1:1,000; rabbit polyclonal; cat. no. 9542T; all were obtained from Cell Signaling Technology, Beverly, MA, USA.

Cell line and cell culture. The HepaRG cell line was purchased from Shanghai Guan\&Dao Biological Engineering Co., Ltd., Jinan, China. The cells were cultured in RPMI-1640 medium (Gibco; Thermo Fisher Scientific, Inc., Waltham, MA, USA) supplemented with $10 \%$ fetal bovine serum (FBS), antibiotics (100 U/ml penicillin and $100 \mu \mathrm{g} / \mathrm{ml}$ streptomycin). Cells were maintained at $37^{\circ} \mathrm{C}$ under a humidified atmosphere containing $5 \% \mathrm{CO}_{2}$.

Cell viability assay. Cell viability was measured using the MTT assay as previously described (32). HepaRG cells were seeded in 96 -well microplates $\left(5 \times 10^{3}\right.$ cells/well) and incubated at $37^{\circ} \mathrm{C}$ overnight. After incubation with emodin $(20,40$ and $80 \mu \mathrm{M}$ ) for 24 and $48 \mathrm{~h}$ at $37^{\circ} \mathrm{C}, 100 \mu \mathrm{l}$ of MTT was added into each well and incubated for $4 \mathrm{~h}$ at $37^{\circ} \mathrm{C}$ in a $5 \% \mathrm{CO}_{2}$ incubator. Subsequently, DMSO (150 $\mu \mathrm{l})$ was added to dissolve the formazan crystals. Absorbance of the formazan solution was read at $570 \mathrm{~nm}$ in a microplate reader (Multiskan GO; Thermo Fisher Scientific, Inc.). For the lactate dehydrogenase (LDH) assay, the cells were cultured overnight and then treated with serial concentrations of emodin for $24 \mathrm{~h}$. The LDH enzyme released from cells was quantified by an LDH assay kit according to the manufacturer's protocol. The absorbance of the supernatant was measured at $490 \mathrm{~nm}$ by fluorescent plate reader.

DAPI staining. The occurrence of apoptosis was evaluated by DAPI staining. Cells $\left(4.0 \times 10^{5}\right.$ cells/well) were seeded and incubated with different concentrations of emodin for $24 \mathrm{~h}$. Following treatment, the cells were washed with PBS and fixed with 4\% paraformaldehyde (Sigma-Aldrich) for $15 \mathrm{~min}$ at room temperature, and then stained in the dark with a DAPI solution for $10 \mathrm{~min}$ at room temperature. Thereafter, the cells were washed with PBS and photographed under an inverted fluorescence microscopy (Olympus IX71; Olympus, Tokyo, Japan).

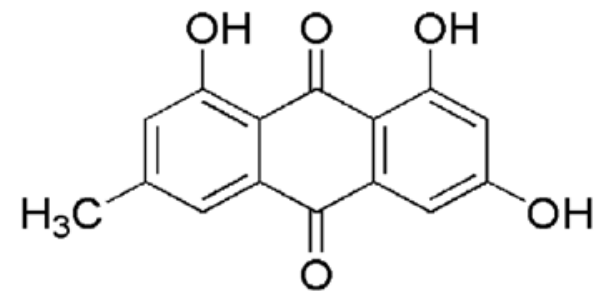

Figure 1. Chemical structure of emodin (1,3,8-trihydroxy-6-methylanthraquinone).

Annexin V/PI staining assay. Annexin V/PI staining was used to confirm the emodin-induced apoptosis in HepaRG cells (33). HepaRG cells $\left(4.0 \times 10^{5}\right.$ cells/well) were seeded in 6-well plates and treated with various concentrations of emodin (20,40 and $80 \mu \mathrm{M})$. After $24 \mathrm{~h}$, the cells were collected with trypsinization, washed with PBS and resuspended in binding buffer $(295 \mu \mathrm{l})$. Annexin V-FITC $(5 \mu \mathrm{l})$ and propidium iodide (PE) $(10 \mu \mathrm{l})$ were added and incubated for $15 \mathrm{~min}$ at $37^{\circ} \mathrm{C}$ in the dark. Finally, the apoptotic cells were immediately analyzed by flow cytometry (BD FACSCanto II; BD Biosciences, San Jose, CA, USA). At least 10,000 cells per sample were acquired to ensure adequate data.

Determination of intracellular ROS. ROS generation was measured with an oxidation-sensitive probe DCFH-DA, which is cleaved by nonspecific esterases and yields highly fluorescent 2,7-dichlorofluorescein (DCF) upon oxidation by ROS. After treatment with emodin $(20,40$ and $80 \mu \mathrm{M})$ or control medium treatment for $24 \mathrm{~h}$, the cells were washed twice in PBS. Then, they were loaded with DCFH-DA $(10 \mu \mathrm{M})$ and incubated for $30 \mathrm{~min}$ at $37^{\circ} \mathrm{C}$ in the dark (34). Thereafter, the cells were harvested and washed twice with PBS, and the oxidation-induced increase in DCF fluorescence was subsequently measured by flow cytometry.

Analysis of mitochondrial membrane potential $(\Delta \Psi m)$. Changes in $\Delta \Psi m$ were examined with the mitochondrial-specific lipophilic cationic fluorescent dye JC-1, which is capable of selective entrance into the mitochondria. Briefly, HepaRG cells $\left(4.0 \times 10^{5}\right.$ cells/well $)$ were plated in 6 -well culture plates and treated with different concentrations of emodin $(20,40$ and $80 \mu \mathrm{M})$ for $24 \mathrm{~h}$ at $37^{\circ} \mathrm{C}$. Subsequently, the cells were collected and incubated with JC-1 $(10 \mu \mathrm{M})$ for $30 \mathrm{~min}$ at $37^{\circ} \mathrm{C}$ in the dark. The cells were then washed twice with PBS and subsequently analyzed using flow cytometry (35).

Cell cycle analysis. HepaRG cells $\left(4.0 \times 10^{5}\right.$ cells/well) were incubated in 6-well plates and treated with different concentrations of emodin $(20,40$ and $80 \mu \mathrm{M})$ for $24 \mathrm{~h}$ at $37^{\circ} \mathrm{C}$. After treatment, the cells were collected and fixed with $70 \%$ ice-cold ethanol at $4^{\circ} \mathrm{C}$ at least for $24 \mathrm{~h}$, and then stained with $\mathrm{PI} / \mathrm{R}$ Nase A staining buffer solution for $30 \mathrm{~min}$ at $37^{\circ} \mathrm{C}$ in the dark (36). The resulting suspension was passed through a nylon mesh filter and analyzed by flow cytometry.

Western blot analysis. HepaRG cells were plated in 6-well plates and treated as described above. The cells 
A
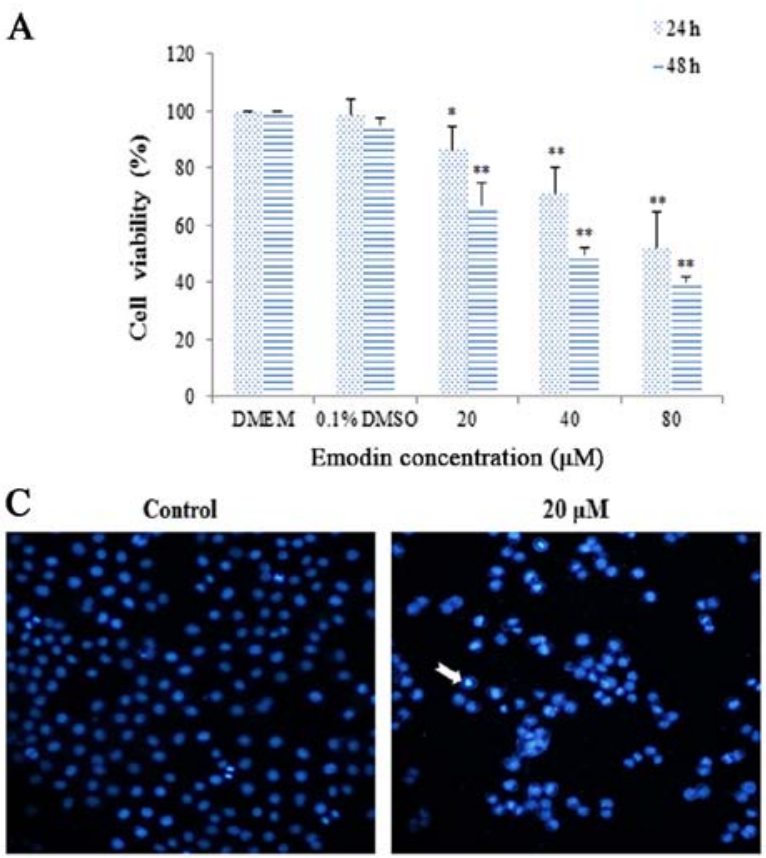

B
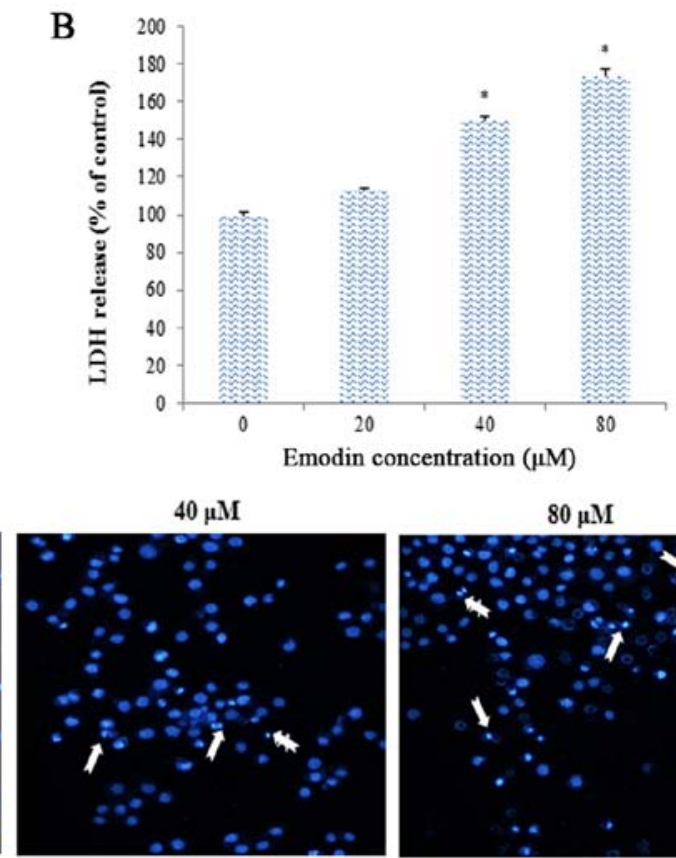

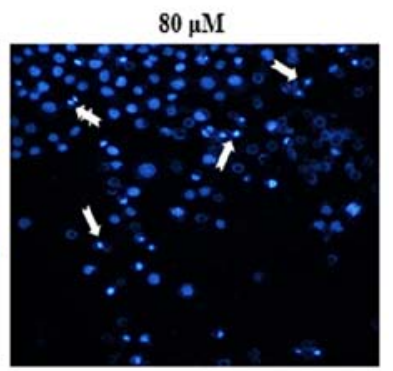

Figure 2. Cell viability and morphology of HepaRG cells after treatment with different concentrations of emodin. (A) Cell viability was evaluated by the MTT assay. (B) The cell cytotoxicity was assessed by LDH assay. (C) The nuclear morphology of HepaRG cells was observed by DAPI staining. The arrow markers represent the apoptotic cells. Data are expressed as the mean \pm SD of three separate experiments $\left({ }^{*} \mathrm{P}<0.05,{ }^{* *} \mathrm{P}<0.01\right.$ vs. vehicle control). LDH, lactate dehydrogenase.

were harvested, lysed with RIPA buffer for $30 \mathrm{~min}$ on ice. Lysates were centrifuged at $12,000 \mathrm{rpm}$ for $10 \mathrm{~min}$ at $4^{\circ} \mathrm{C}$. Total protein concentration was determined using the bicinchoninic acid assay (BCA) protein assay kit. In a parallel experiment, cytosolic and mitochondrial extracts were prepared using the ProteoExtract ${ }^{\circledR}$ Cytosol/Mitochondria Fractionation Kit (Millipore, Billerica, MA, USA) following the manufacturer's protocol. An equal amount of proteins was separated by electrophoresis on SDS-polyacrylamide gels (SDS-PAGE) and transferred onto polyvinylidene fluoride (PVDF) membranes. The membranes were blocked with TBST buffer containing 5\% skim milk for $1 \mathrm{~h}$, and then incubated with specific primary antibodies overnight at $4^{\circ} \mathrm{C}$. After three times washing with TBST buffer, the membranes were further incubated with the horseradish peroxidase-conjugated secondary antibodies (cat. no. 3700; Cell Signaling Technology) at room temperature for $1 \mathrm{~h}(37,38)$. An enhanced ECL detection system was used for visualization of target proteins (iNtRON Biotechnology, Seongnam, Korea).

Statistical analysis. All experiments were performed in triplicates, and the results are expressed as mean \pm standard deviation (SD). Statistical analysis was analyzed by One-Way ANOVA analysis and LSD test using SPSS 17.0 software (SPSS, Inc., Chicago, IL, USA). Differences with a probability value $(\mathrm{P})<0.05$ were considered to be statistically significant.

\section{Results}

Emodin inhibits cell viability in the HepaRG cells. MTT assay indicated that emodin inhibited the proliferation of HepaRG cells in a dose- and time-dependent manner (Fig. 2A). When HepaRG cells were treated with $80 \mu \mathrm{M}$ of emodin, the cell viabilities were $-52.21 \%$ after $24 \mathrm{~h}$ of treatment, and then reduced to $40.32 \%$ after $48 \mathrm{~h}$ of treatment, respectively. Furthermore, emodin treatment also caused LDH leakage observed on HepaRG cells in a dose-dependent manner (Fig. 2B). To further verify emodin-induced apoptosis in HepaRG cells, we analyzed morphological nuclear changes using DAPI staining. The results showed that a significant number of cells with chromatin condensation and nuclear fragmentation were observed compared to the untreated control (Fig. 2C).

Emodin induces the apoptosis of HepaRG cells. Annexin V-FITC/PI double staining was performed to quantify emodin-induced apoptosis. The percentage of viable cells was significantly decreased after treatment with emodin for $24 \mathrm{~h}$. Furthermore, both the early and late apoptotic cell populations increased 7.5- and 8.3-fold in the HepaRG cells, respectively. However, pretreatment with NAC successfully reversed the apoptosis induction (Fig. 3A and B). Thus, these results indicate that emodin appears to trigger apoptotic cell death in HepaRG cells.

Emodin increases ROS generation in the HepaRG cells. ROS plays an important role in the process of cell apoptosis. To measure the effect of emodin on the ROS level, the cells were stained with DCFH-DA and analyzed by flow cytometry. Compared with the control group, the results showed that the ROS level was increased dose-dependently in HepaRG cells after emodin treatment. However, after pre-treatment with NAC for $1 \mathrm{~h}$, ROS generation was significantly attenuated (Fig. 4A and B). 
A
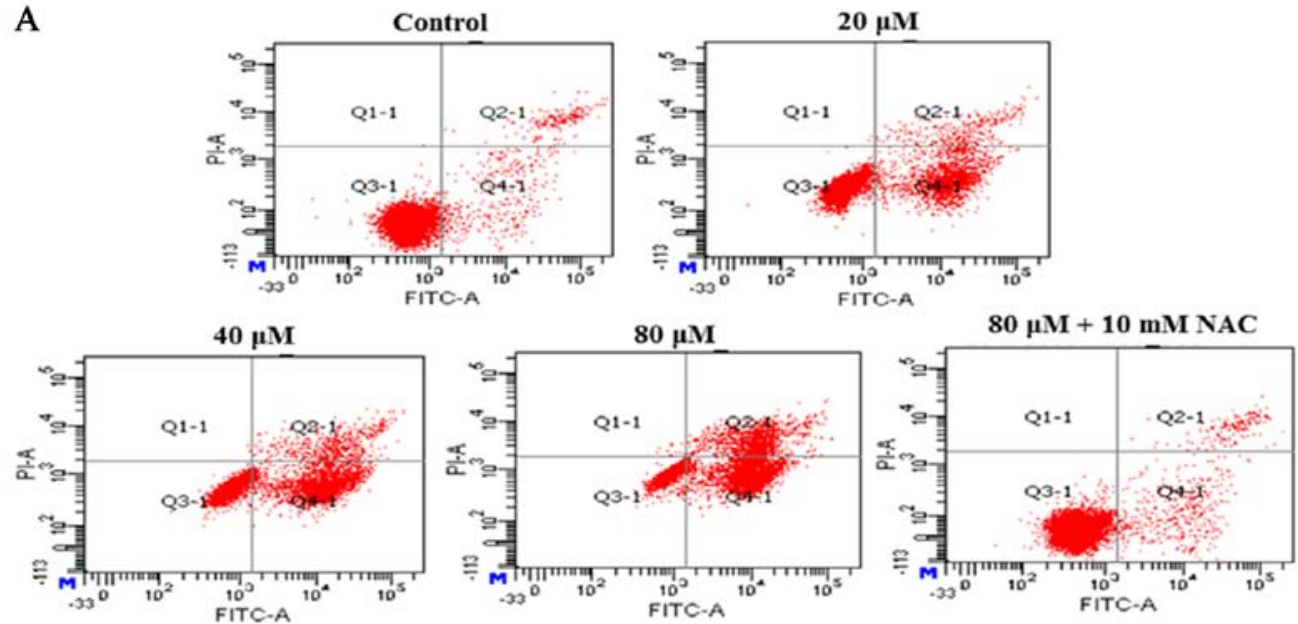

B

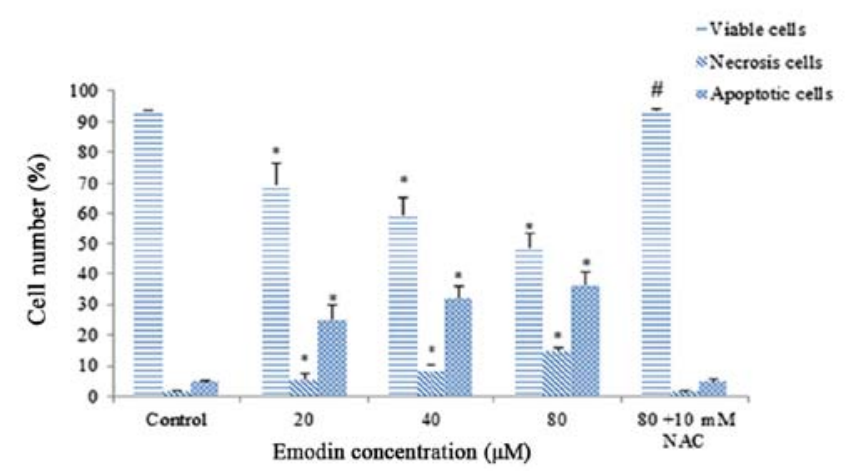

Figure 3. HepaRG cells were incubated with various concentrations of emodin for $24 \mathrm{~h}$, with or without NAC pretreatment. (A) Representative image of flow cytometry detection of apoptosis with Annexin V/PI in the different groups. (B) Column bar graph of the mean cell florescence for viable, apoptotic and necrotic cells. Data are expressed as the mean $\pm \mathrm{SD}$ of three separate experiments ( $\mathrm{P}<0.05 \mathrm{vs.} \mathrm{control;}{ }^{*} \mathrm{P}<0.05$ vs. the $80 \mu \mathrm{M}$ emodin-treated group). NAC, $N$-acetylcysteine.

A
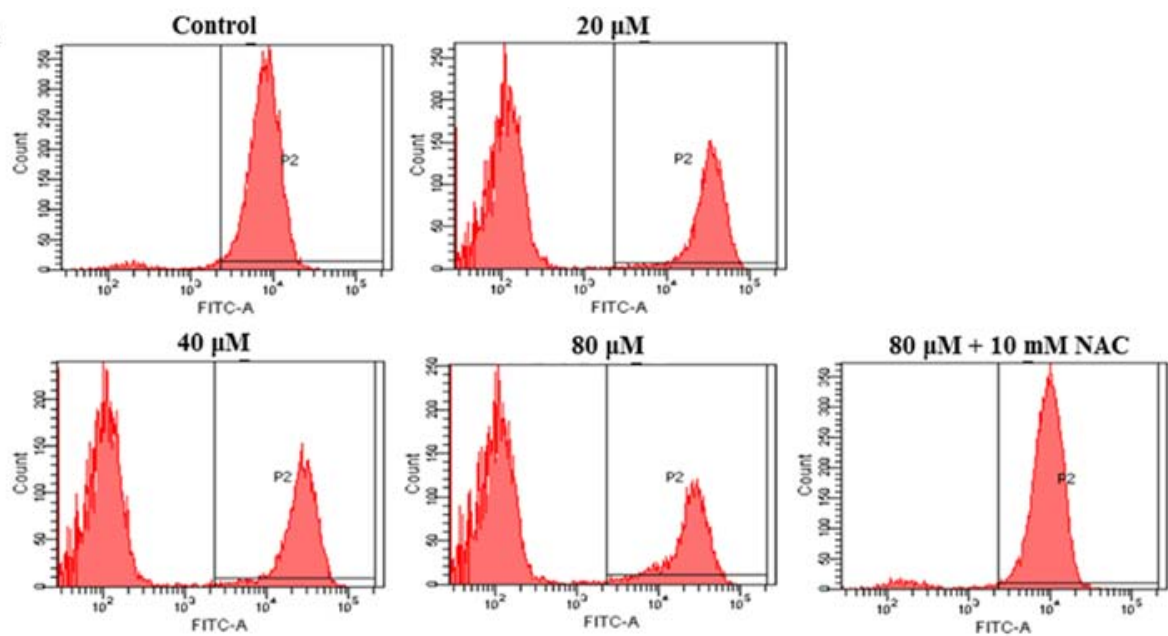

B

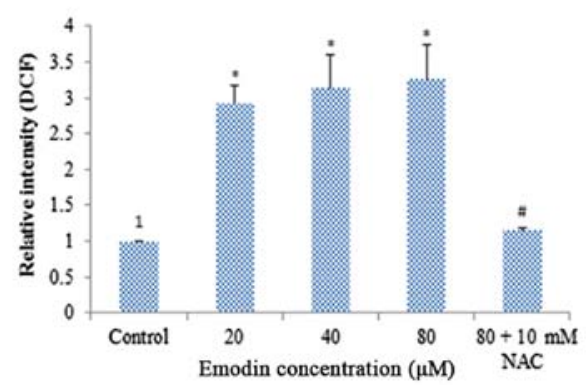

Figure 4. ROS generation of HepaRG cells induced by various concentrations of emodin for $24 \mathrm{~h}$, with or without NAC pretreatment. (A) Representative image of flow cytometry detection with DCFH-DA in HepaRG cells. (B) Column bar graph of the mean cell florescence for DCFH-DA. Data are expressed as the mean \pm SD of three separate experiments ("P<0.05 vs. the control; ${ }^{*} \mathrm{P}<0.05$ vs. the $80 \mu \mathrm{M}$ emodin-treated group). ROS, reactive oxygen species; NAC, $N$-acetylcysteine. 
A

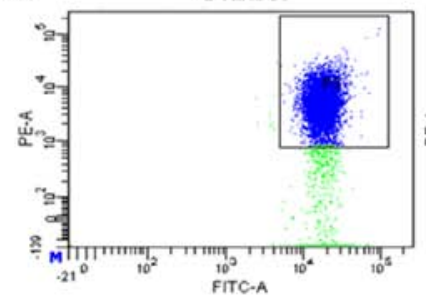

$40 \mu \mathrm{M}$

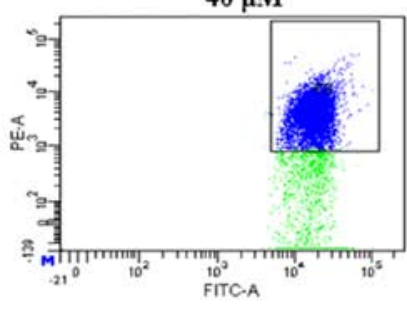

$20 \mu \mathrm{M}$

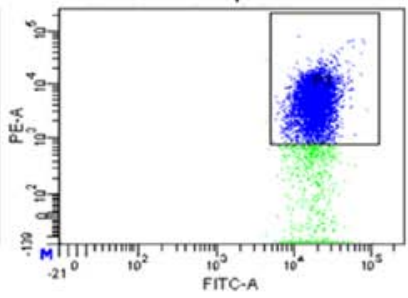

$80 \mu \mathrm{M}$

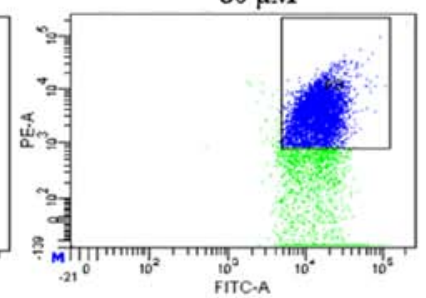

B

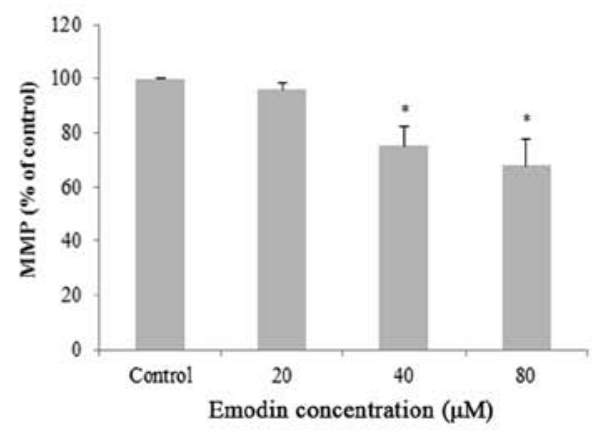

$\mathrm{C}$

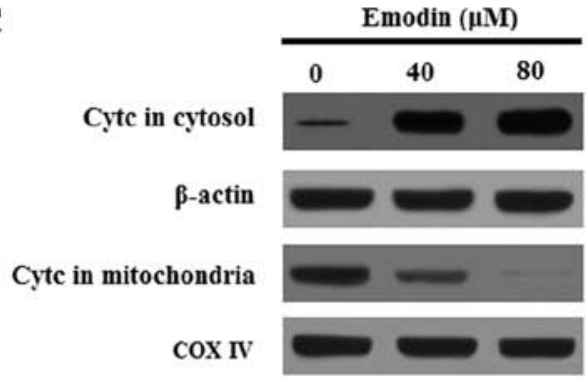

D

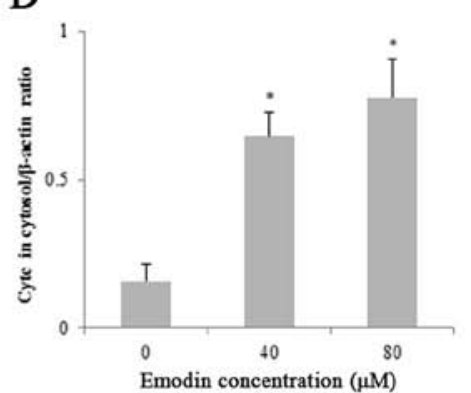

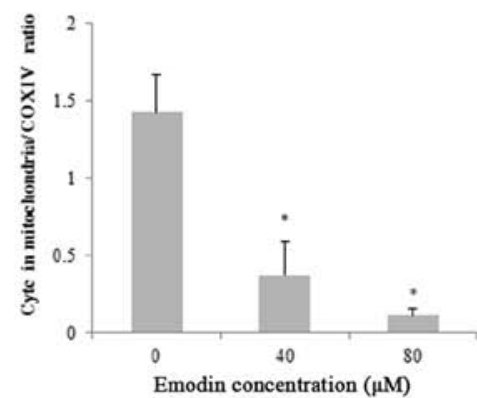

Figure 5. MMP of HepaRG cells induced by various concentrations of emodin for 24 h. (A) Representative image of flow cytometry detection with JC-1 in HepaRG cells. (B) Column bar graph of the mean cell florescence for JC-1. (C) The protein expression of cytochrome $c$ (cytc) in mitochondria and the cytosol was measured by western blotting. $\beta$-actin and COX IV were analyzed as the internal control for the cytosolic and mitochondrial fractions, respectively. (D) The protein bands were quantified and statistically analyzed. Data for each image are expressed as the mean \pm SD of three separate experiments ( $\mathrm{P}<0.05$ vs. vehicle control). MMP, mitochondrial membrane potential.

Emodin reduced $\Delta \Psi m$ and induces cytochrome c release from mitochondria. To investigate the effect of emodin on mitochondrial functions of HepaRG cells. $\Delta \Psi \mathrm{m}$ was measured using JC-1 fluorescence staining by flow cytometry. Treatment with emodin induced the loss of mitochondrial membrane potential (MMP $\Delta \Psi \mathrm{m}$ ) in HepaRG cells in a dose-dependent manner (Fig. 5A and B). Furthermore, we investigated the release of cytochrome $c$ by Western blot analysis. The level of cytochrome $c$ was significantly increased in the cytosol fraction, while markedly decreased in the mitochondria after treatment with emodin for $24 \mathrm{~h}$ (Fig. 5C and D). Taken together, emodin induces apoptosis through a change in MMP and regulation of apoptosis-related proteins in HepaRG cells.

Emodin arrests the cell cycle at the $S$ and G2/M phases in HepaRG cells. To investigate the effects of emodin on cell cycle distribution, HepaRG cells were stained with PI and then analyzed by flow cytometry. Compared with the control group, after $24 \mathrm{~h}$ of emodin $(40 \mu \mathrm{M})$ exposure, the percentage of cells in the $\mathrm{S}$ and $\mathrm{G} 2 / \mathrm{M}$ phases increased from $31.74 \pm 2.46$ to $52.12 \pm 2.00 \%$ and $6.14 \pm 1.72$ to $15.65 \pm 1.79 \%$, respectively (Fig. 6A and B). Moreover, we investigated the expression levels of the proteins involved in the $S$ and $G 2 / M$ phase progression. The results demonstrated that the expression levels of p53, p21 and cyclin E proteins were significantly increased. However, other cyclin proteins (cyclin A and CDK2) were downregulated in HepaRG cells (Fig. 6C and D). This experiment demonstrated that emodin arrested the cell cycle at the $\mathrm{S}$ and $\mathrm{G} 2 / \mathrm{M}$ phases in the HepaRG cells.

Emodin induces apoptosis through activation of the mitochondrial signaling pathway in HepaRG cells. To explore the possible mechanisms of emodin-induced apoptosis in HepaRG cells, we evaluated the expression of various proteins involved in the mitochondrial signaling pathway by Western blot analysis. We evaluated the expression of Bcl-2 family associated proteins and caspases, which are involved in the mitochondrial signaling pathway. Treatment with emodin significantly increased the expression of pro-apoptotic Bax and decreased the expression of anti-apoptotic Bcl-2 in a dose-dependent manner, thereby significantly resulting in an elevated $\mathrm{Bax} / \mathrm{Bcl}-2$ ratio. Moreover, caspases are the most important effector molecules for the execution of apoptosis. Compared with the vehicle-treated control group, emodin treatment obviously enhanced the expression of cleaved caspase-3, -9, Bax and PARP (Fig. 7A and B). These results indicate that emodin may induce apoptosis in HepaRG cells via the mitochondrial caspase-dependent pathway. 

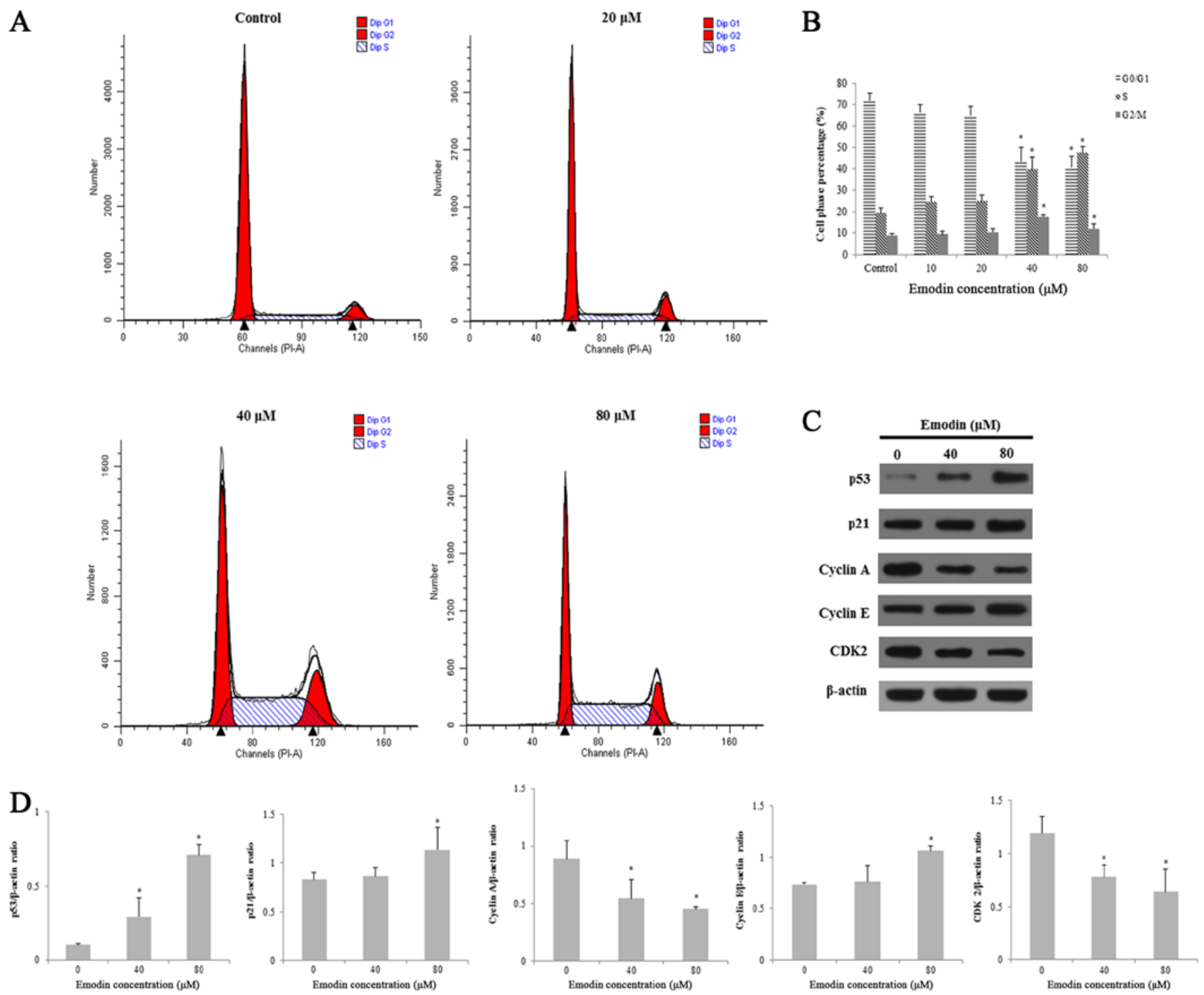

Figure 6. The cell cycle distribution of HepaRG cells induced by various concentrations of emodin for $24 \mathrm{~h}$. (A) Emodin induced cell cycle arrest at the $\mathrm{S}$ and G2/M phases. (B) Column bar graph of each phase of the cell cycle is shown. (C) The related protein expression levels were determined by western blotting. Actin was used as an internal control. (D) The protein bands were quantified and statistically analyzed. Data for each image are expressed as the mean \pm SD of three separate experiments ( $\mathrm{P}<0.05$ vs. the vehicle control).

\section{Discussion}

Emodin is a naturally occurring anthraquinone present in various traditional medicinal plants including Polygonum multiflorum Thunb., Polygonum cuspidatum, Rheum palmatum L. and Cassia occidentalis (9-12). Previous studies have demonstrated that emodin possessed many pharmacological properties, such as antiviral, anti-allergic, antiosteoporotic, anti-diabetic, immunosuppressive and neuroprotective activities (19-25). However, previous studies have demonstrated that emodin causes a variety of toxic effects such as genotoxicity (39), reproductive toxicity (40), nephrotoxicity (37) and hepatotoxicity $(12,28,29,41,42)$. In the present study, we utilized a novel cell model (HepaRG cells) to investigate the cytotoxicity of emodin and the underlying molecular mechanisms.

Compared with the control treatment, emodin significantly decreased the viability of HepaRG cells in a dose and time-dependent manner. DAPI and Annexin V/PI double staining further confirmed that emodin inhibited the growth of HepaRG cells in a dose-dependent manner via apoptosis, as confirmed by cell shrinkage, apoptotic body formation and DNA fragmentation. Thus, the results showed that the cytotoxic effect on HepaRG cells induced by emodin was attributed to apoptosis.

ROS are generated as by-products of mitochondrial respiration or precise oxidases and play an important role in apoptosis signaling. Stimulated ROS production could result in oxidative stress and induce cellular damage (43). Emodin treatment effectively triggered production of intracellular ROS, which was reversed by pre-treatment with NAC. These results indicate that the change in intracellular ROS by emodin was at least in part related to apoptosis in the HepaRG cells. Furthermore, excessive ROS can induce oxidative DNA damage followed by cell cycle process arrest or delay (44). In the present study, we found that the mechanism of action of 
A

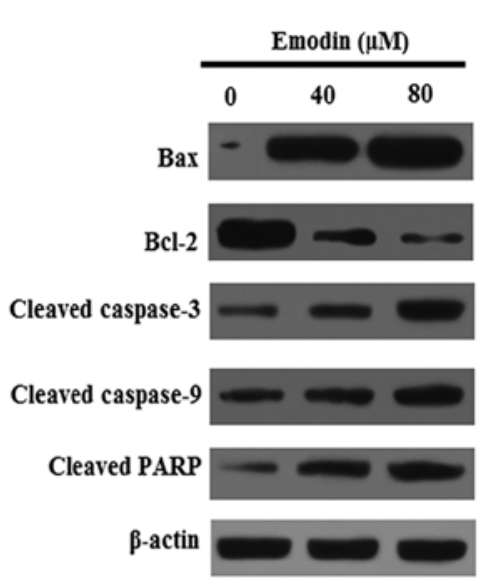

B
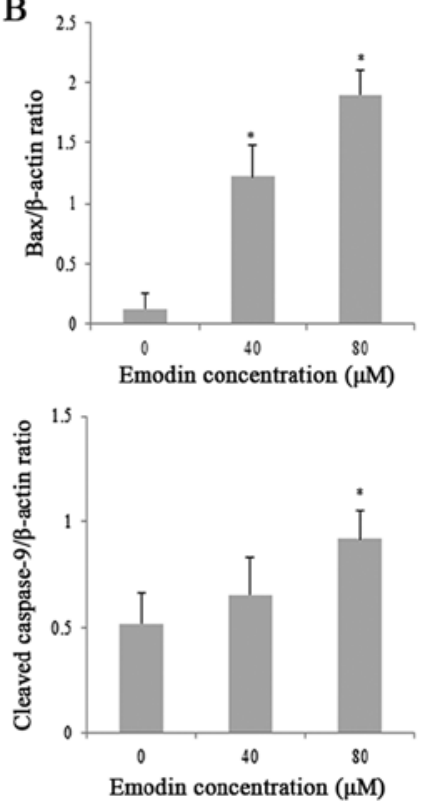
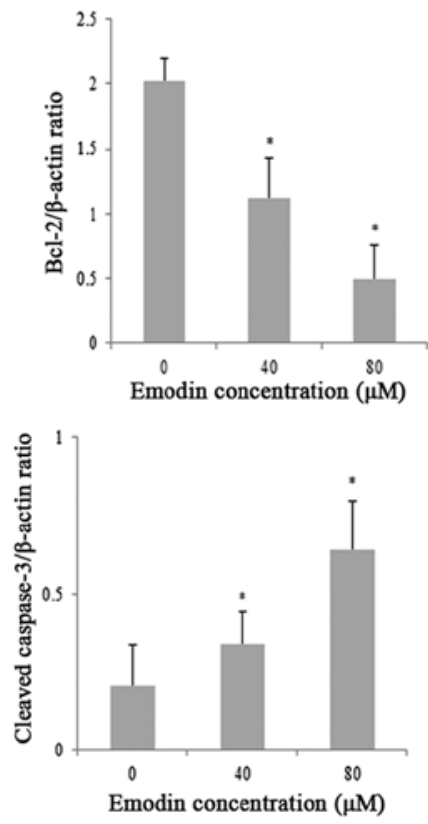

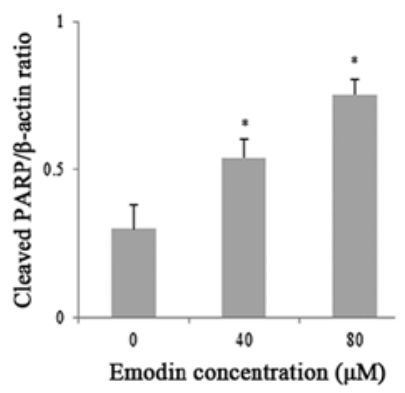

Figure 7. The levels apoptosis-related proteins in the HepaRG cells induced by various concentrations of emodin for $24 \mathrm{~h}$. (A) Expression of apoptosis-related proteins after treatment with emodin was determined. (B) The protein bands were quantified and statistically analyzed. Data for each image are expressed as the mean $\pm \mathrm{SD}$ of three separate experiments (" $\mathrm{P}<0.05$ vs. the vehicle control). Actin was used as an internal control.

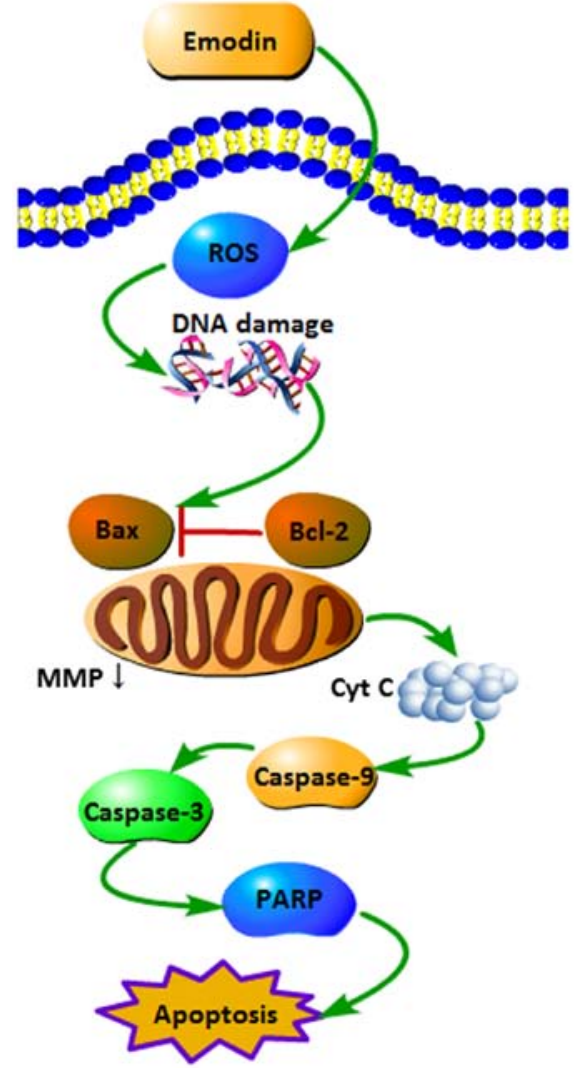

Figure 8. Schematic mechanism showing the apoptotic signaling pathway induced by emodin in HepaRG cells. ROS, reactive oxygen species; cytc, cytochrome $c$; MMP, mitochondrial membrane potential.

emodin in HepaRG cells was similar to that of aloe-emodin, suggesting that cell cycle arrest might be one of the mechanisms underlying the cytotoxic effect on HepaRG cells induced by emodin (45). Mitochondrial impairment or dysfunction could rapidly induce the inhibition of cell survival and proliferation (46). Our data suggest that emodin induced the collapse of MMP with an increased release of cytochrome $c$ from the mitochondria into the cytosol, indicating clearly that the mitochondria play an essential role in emodin-induced apoptosis of HepaRG cells. These results are in accordance with our previous study (45), which demonstrated that aloe-emodin inhibited HepaRG proliferation by the induction of apoptosis through the intrinsic mitochondrial pathway.

Apoptosis initiated by increased ROS production after emodin treatment might induce apoptosis-related protein change. Compared with the control cells, our data suggested that the treatment of HepaRG cells with emodin significantly increased the protein expression levels of p53, p21, Bax, cleaved caspases-3, and -9 and PARP, while emodin decreased Bcl-2 levels. Furthermore, emodin promoted cytochrome $c$ release from mitochondria into the cytosol. Previous studies have shown that emodin induced apoptosis in cancer cells through the mitochondrial-dependent apoptotic pathway (47-49), which was consistent with our experiments. In addition, emodin induced hepatocellular carcinoma cell apoptosis through the mitogen-activated protein kinase (MAPK) and phosphoinositide 3-kinase (PI3K)/AKT signaling pathways $(15,50)$.

To the best of our knowledge, this is the first report of emodin-induced apoptosis in HepaRG cells. Based on our data, we summarize the signaling pathways of emodin-induced apoptosis in HepaRG cells (Fig. 8). In summary, the present study demonstrated that emodin inhibited the proliferation of HepaRG cells and induced cell cycle arrest and apoptosis through the ROS-mediated mitochondrial pathway. Conversely, pre-treatment with NAC partly inhibited the emodin-induced apoptosis via the downregulation of ROS-mediated signal cascades. 


\section{Acknowledgements}

The authors would like to acknowledge the helpful comments on this manuscript that were provided by the reviewers.

\section{Funding}

The present study was financially supported by the National Natural Science Foundation of China (no. 81673609).

\section{Availability of data and materials}

The datasets generated and/or analysed during the present study are not publicly available due to protection of participant confidentiality but are available from the corresponding author on reasonable request.

\section{Authors' contributions}

XD and JN designed the research; BN, JF, XY, and LY conducted the main experiments; XLe and XLi performed the data analysis. All authors have reviewed and approved the final version of the manuscript.

\section{Ethics approval and consent to participate}

Ethical approval was granted by the Committee on Animal Care and Usage of the Beijing University of Chinese Medicine, Beijing, China.

\section{Patient consent for publication}

Not applicable.

\section{Competing interests}

The authors declare that they have no competing interests.

\section{References}

1. Wong RS: Apoptosis in cancer: From pathogenesis to treatment J Exp Clin Cancer Res 30: 87, 2011.

2. Ferrín G, Linares CL and Muntané J: Mitochondrial drug targets in cell death and cancer. Curr Pharm Design 17: 2002-2016, 2011

3. Dong X, Fu J, Yin X, Yang CJ and Ni J: Aloe-emodin induces apoptosis in human liver HL-7702 cells through Fas death pathway and the mitochondrial pathway by generating reactive oxygen species. Phytother Res 31: 927-936, 2017.

4. Bhimani RS, Troll W, Grunberger D and Frenkel K: Inhibition of oxidative stress in HeLa cells by chemopreventive agents. Cancer Res 53: 4528-4533, 1993.

5. Wu CC and Bratton S: Regulation of the intrinsic apoptosis pathway by reactive oxygen species. Antioxid Redox Sign 19: 546-558, 2013.

6. D'Autréaux B and Toledano MB: ROS as signalling molecules: Mechanisms that generate specificity in ROS homeostasis. Nat Rev Mol Cell Bio 8: 813-824, 2007.

7. Tomek MT, Akiyama T and Dass CR: Role of Bcl-2 in tumour cell survival and implications for pharmacotherapy. J Pharm Pharmacol 64: 1695-1702, 2012.

8. Krieser RJ and Eastman A: Cleavage and nuclear translocation of the caspase 3 substrate Rho GDP-dissociation inhibitor, D4-GDI, during apoptosis. Cell Death Differ 6: 412-419, 1999.
9. Wang JB, Zhao HP, Zhao YL, Jin C, Liu DJ, Kong WJ, Zhang L, Wang HJ and Xiao XH: Hepatotoxicity or hepatoprotection? Pattern recognition for the paradoxical effect of the Chinese herb Rheum palmatum L. in treating rat liver injury. PLoS One 6: e24498, 2011.

10. Lee MH, Kao L and Lin C: Comparison of the antioxidant and transmembrane permeative activities of the different Polygonum cuspidatum extracts in phospholipid-based microemulsions. J Agr Food Chem 59: 9135-9141, 2011.

11. Wang M, Zhao R, Wang W, Mao X and Yu J: Lipid regulation effects of Polygoni Multiflori Radix, its processed products and its major substances on steatosis human liver cell line L02. J Ethnopharmacol 139: 287-293, 2012.

12. Panigrahi GK, Ch R, Mudiam MK, Vashishtha VM, Raisuddin S and Das M: Activity-guided chemo toxic profiling of Cassia occidentalis $(\mathrm{CO})$ seeds: Detection of toxic compounds in body fluids of CO-exposed patients and experimental rats. Chem Res Toxicol 28: 1120-1132, 2015.

13. Liu A, Chen H, Wei W, Ye S, Liao W, Gong J, Jiang Z, Wang L and Lin S: Antiproliferative and antimetastatic effects of emodin on human pancreatic cancer. Oncol Rep 26: 81-89, 2011.

14. Huang PH, Huang CY, Chen MC, Lee YT, Yue CH, Wang HY and Lin H: Emodin and aloe-emodin suppress breast cancer cell proliferation through ER $\alpha$ inhibition. Evid-Based Complement Alternat Med 2013: 376123, 2013.

15. Lin W, Zhong M, Yin H, Chen Y, Cao Q, Wang C and Ling C: Emodin induces hepatocellular carcinoma cell apoptosis through MAPK and PI3K/AKT signaling pathways in vitro and in vivo. Oncol Rep 36: 961-967, 2016

16. Su J, Yan Y, Qu J, Xue X, Liu Z and Cai H: Emodin induces apoptosis of lung cancer cells through ER stress and the TRIB3/NF-кB pathway. Oncol Rep 37: 1565-1572, 2017.

17. Sun $Z$ and BU P: Downregulation of phosphatase of regenerating liver-3 is involved in the inhibition of proliferation and apoptosis induced by emodin in the SGC-7901 human gastric carcinoma cell line. Exp Ther Med 3: 1077-1081, 2012.

18. Cha TL, Qiu L, Chen CT, Wen Y and Hung MC: Emodin down-regulates androgen receptor and inhibits prostate cancer cell growth. Cancer Res 65: 2287-2295, 2005.

19. Schwarz S, Wang K, Yu W, Sun B and Schwarz W: Emodin inhibits current through SARS-associated coronavirus 3a protein. Antivir Res 90: 64-69, 2011.

20. Chukwujekwu JC, Coombes PH, Mulholland DA and Staden J: Emodin, an antibacterial anthraquinone from the roots of Cassia occidentalis. S Afr J Bot 72: 295-297, 2006.

21. Wang W, Zhou Q, Liu L and Zou K: Anti-allergic activity of emodin on IgE-mediated activation in RBL-2H3 cells. Pharmacol Rep 64: 1216-1222, 2012.

22. Yang F, Yuan PW, Hao YQ and Lu ZM: Emodin enhances osteogenesis and inhibits adipogenesis. BMC Complement Altern Med 14: 74, 2014.

23. Song P, Kim JH, Ghim J, Yoon JH, Lee A, Kwon Y, Hyun H, Moon HY, Choi HS, Berggren PO, et al: Emodin regulates glucose utilization by activating AMP-activated protein kinase. J Biol Chem 288: 5732-5742, 2013.

24. Liu YX, Shen NY, Liu C and Lv Y: Immunosuppressive effects of emodin: An in vivo and in vitro study. Transplant Proc 41: 1837-1839, 2009.

25. Gao Y, Liu H, Deng L, Zhu G, Xu C, Li G, Liu S, Xie J, Liu J, Kong $\mathrm{F}$, et al: Effect of emodin on neuropathic pain transmission mediated by $\mathrm{P} 2 \mathrm{X} 2 / 3$ receptor of primary sensory neurons. Brain Res Bull 84: 406-413, 2011.

26. National Toxicology Program: NTP Toxicology and carcinogenesis studies of Emodin (CAS NO. 518-82-1) feed studies in F344/N rats and B6C3F1 mice. Natl Toxicol Program Tech Rep Ser 493: 1-278, 2001.

27. Müller SO, Eckert I, Lutz WK and Stopper H: Genotoxicity of the laxative drug components emodin, aloe-emodin and danthron in mammalian cells: Topoisomerase II mediated? Mutat Res 371: 165-173, 1996.

28. Panigrahi GK, Suthar MK, Verma N, Asthana S, Tripathi A, Gupta SK, Saxena JK, Raisuddin S and Das M: Investigation of the interaction of anthraquinones of Cassia occidentalis seeds with bovine serum albumin by molecular docking and spectroscopic analysis: Correlation to their in vitro cytotoxic potential. Food Res Int 77: 368-377, 2015.

29. Wang JB, Ma YG, Zhang P, Jin C, Sun YQ, Xiao XH, Zhao YL and Zhou CP: Effect of processing on the chemical contents and hepatic and renal toxicity of rhubarb studied by canonical correlation analysis. Yao Xue Xue Bao 44: 885-890, 2009 (In Chinese). 
30. Andersson TB, Kanebratt KP and Kenna JG: The HepaRG cell line: A unique in vitro tool for understanding drug metabolism and toxicology in human. Expert Opin Drug Metab Toxicol 8: 909-920, 2012.

31. Anthérieu S, Chesné C, Li R, Guguen-Guillouzo C and Guillouzoa A: Optimization of the HepaRG cell model for drug metabolism and toxicity studies. Toxicol In Vitro 26: 1278-1285, 2012.

32. Wang C, Wu X, Chen M, Duan W, Sun L, Yan M and Zhang L: Emodin induces apoptosis through caspase 3-dependent pathway in HK-2 cells. Toxicology 231: 120-128, 2007.

33. Zhu Y, Jiang Y, Shi L, Du L, Xu X, Wang E, Sun Y, Guo X, Zou B, Wang H, et al: 7-O-Geranylquercetin induces apoptosis in gastric cancer cells via ROS-MAPK mediated mitochondrial signaling pathway activation. Biomed Pharmacothe 87: 527-538, 2017.

34. Zuo D, Duan Z, Jia Y, Chu T, He Q, Yuan J, Dai W, Li Z, Xing L and Wu Y: Amphipathic silica nanoparticles induce cytotoxicity through oxidative stress mediated and p53 dependent apoptosis pathway in human liver cell line HL-7702 and rat liver cell line BRL-3A. Colloids Surf B Biointerfaces 145: 232-240, 2016.

35. Wang J, Wang QL, Nong XH, Zhang XY, Xu XY, Qi SH and Wang YF: Oxalicumone A, a new dihydrothiophene-condensed sulfur chromone induces apoptosis in leukemia cells through endoplasmic reticulum stress pathway. Eur J Pharmacol 783: 47-55, 2016.

36. Zhao Y, Zhang C and Suo Y: MMPT as a reactive oxygen species generator induces apoptosis via the depletion of intracellular GSH contents in A549 cells. Eur J Pharmacol 688: 6-13, 2012.

37. Wang C, Dai X, Liu H, Yi H, Zhou D, Liu C, Ma M, Jiang Z and Zhang L: Involvement of PPAR $\gamma$ in emodin-induced HK-2 cell apoptosis. Toxicol In Vitro 29: 228-233, 2015.

38. Huang H, Liu C, Fu X, Zhang S, Xin Y, Li Y, Xue L, Cheng X and Zhang H: Microcystin-LR induced apoptosis in rat sertoli cells via the mitochondrial caspase-dependent pathway: Role of reactive oxygen species. Front Physiol 7: 397, 2016.

39. Li Y, Luan Y, Qi X, Li M, Gong L, Xue X, Wu X, Wu Y, Chen M, Xing G, et al: Emodin triggers DNA double-strand breaks by stabilizing topoisomerase II-DNA cleavage complexes and by inhibiting ATP hydrolysis of topoisomerase II. Toxicol Sci 118: 435-443, 2010.

40. Oshida K, Hirakata M, Maeda A, Miyoshi T and Miyamoto Y: Toxicological effect of emodin in mouse testicular gene expression profile. J Appl Toxicol 31: 790-800, 2011.

41. Lin L, Lin H,Zhang M, Ni B, Yin X, Qu C and Ni J: A novel method to analyze hepatotoxic components in Polygonum multiflorum using ultra-performance liquid chromatography-quadrupole time-of-flight mass spectrometry. J Hazard Mater 299: 249-259, 2015.
42. Ma J, Zheng L, He YS and Li HY: Hepatotoxic assessment of Polygoni Multiflori Radix extract and toxicokinetic study of stilbene glucoside and anthraquinones in rats. J Ethnopharmacol 162: 61-68, 2015.

43. Martindale JL and Holbrook NJ: Cellular response to oxidative stress: Signaling for suicide and survival. J Cell Physiol 192: $1-15,2002$.

44. Lv L, Zheng L, Dong D, Xu L, Yin L, Xu Y, Qi Y and Han X: Dioscin, a natural steroid saponin, induces apoptosis and DNA damage through reactive oxygen species: A potential new drug for treatment of glioblastoma multiforme. Food Chem Toxicol 59: 657-669, 2013.

45. Dong $\mathrm{X}, \mathrm{Fu} \mathrm{J}$, Yin $\mathrm{X}, \mathrm{Qu} \mathrm{C}, \mathrm{He} \mathrm{H}$, Yang $\mathrm{C}$ and $\mathrm{Ni} \mathrm{J}$ : Induction of apoptosis in HepaRG cell line by Aloe-Emodin through generation of reactive oxygen species and the mitochondrial pathway. Cell Physiol Biochem 42: 685-696, 2017.

46. Heimlich G, McKinnon AD, Bernardo K, Brdiczka D, Reed JC, Kain R, Krönke M and Jürgensmeier JM: Bax-induced cytochrome $c$ release from mitochondria depends on alpha-helices-5 and -6. Biochem J 378: 247-255. 2004.

47. Ying $\mathrm{J}, \mathrm{Xu} \mathrm{H}, \mathrm{Wu} \mathrm{D}$ and $\mathrm{Wu} \mathrm{X}$ : Emodin induces apoptosis of human osteosarcoma cells via mitochondria- and endoplasmic reticulum stress-related pathways. Int $\mathbf{J}$ Clin Exp Patho 8: 12837-12844, 2015.

48. Ma L and Li WS: Emodin inhibits LOVO colorectal cancer cell proliferation via the regulation of the $\mathrm{Bcl}-2 / \mathrm{Bax}$ ratio and cytochrome $c$. Exp Ther Med 8: 1225-1228, 2014.

49. Xie MJ, Ma YH, Miao L, Wang Y, Wang HZ, Xing YY, $\mathrm{Xi}$ T and Lu YY: Emodin-provoked oxidative stress induces apoptosis in human colon cancer HCT116 cells through a p53-mitochondrial apoptotic pathway. Asian Pac J Cancer Prev 15: 5201-5205, 2014

50. Cui Y, Lu P, Ge S, Liu Q, Zhu D and Liu X: Involvement of PI3K/Akt, ERK and p38 signaling pathways in emodin-mediated extrinsic and intrinsic human hepatoblastoma cell apoptosis. Food Chem Toxicol 92: 26-37, 2016

This work is licensed under a Creative Commons Attribution-NonCommercial-NoDerivatives 4.0 International (CC BY-NC-ND 4.0) License. 